\title{
FLAVIN-CONTAINING MONOOXYGENASE AND ASCORBIC ACID DEFICIENCY
}

\author{
QUALITATIVE AND QUANTITATIVE DIFFERENCES*
}

\author{
JOANNE I. BRODFUEHRER and VINCENT G. ZANNONI $\dagger$ \\ Department of Pharmacology and Department of Environmental and Industrial Health, \\ University of Michigan, Ann Arbor, MI 48109, U.S.A.
}

(Received 29 October 1986; accepted 13 Fehruary 1987)

\begin{abstract}
Ascorbic acid deficiency causes qualitative and quantitative differences in the guinea pig hepatic flavin-containing monooxygenase (FMO). Kinetic studies with purified FMO indicated no significant change in the apparent $K_{m}$ of dimethylaniline or NADPH in ascorbate-supplemented or -deficient animals. Following purification of ascorbate-deficient guinea pig FMO by DEAE-cellulose and blue agarose chromatography, exogenous FAD was required for $15 \%$ of the FMO microsomal activity recovered. In contrast, only $5 \%$ of the total microsomal enzyme recovered from ascorbate-supplemented animals required exogenous FAD. Furthermore, there was an enhanced sensitivity to time-dependent nonlinearity with the purified ascorbate-deficient guinea pig FMO. The degree of time-dependent nonlinearity was related to the concentration of substrate. Also, purified ascorbate-supplemented guinea pig FMO was stable for 4 weeks at $-20^{\circ}$, whereas the ascorbate-deficient enzyme was inactivated. A decrease in the quantity of ascorbate-deficient guinea pig FMO compared to ascorbate-supplemented was indicated by a marked reduction in total FMO activity recovered from blue agarose chromatography and reduced protein staining intensity with SDS-PAGE at 56,000 daltons.
\end{abstract}

The flavin-containing monooxygenase (FMO; EC 1.14.13.8) is a flavoprotein present in most mammalian species, which catalyzes the oxidation of a large variety of nitrogen- and sulfur-containing drugs and environmental chemicals [1-4]. Oxidation of the nucleophilic center for the majority of compounds leads to less toxic derivatives but, depending on the nature of the compound, oxidation may result in the formation of reactive intermediates which could have toxicological consequences $[5,6]$. The enzyme has been purified and characterized from the hepatic tissue of pig, rat and mouse and from rabbit lung [7-9]. Species and tissue differences in catalytic and immunological properties have been reported, suggesting that the FMO can exist as more than a single form [8, 9].

The activity of FMO appears to be under nutritional and hormonal control [10-12]. Recent studies have demonstrated that the FMO is jeopardized in ascorbic acid deficiency [13]. To date it has been shown that guinea pigs maintained on an ascorbic-acid-deficient diet have a significant reduction $(45 \%)$ in the $\mathrm{N}$-oxidation of dimethylaniline, an FMO substrate [13]. Since the quantity of cytochrome P-450 is reduced markedly in ascorbic acid deficiency [14], it was also demonstrated that

* This work was supported, in part, by Grant 23007 from Hoffmann-La Roche, Inc., Nutley, NJ, and a Rackham Dissertation/Thesis Grant from the School of Graduate Studies, University of Michigan.

† Correspondence should be addressed to: Dr. Vincent G. Zannoni, Department of Pharmacology-MS1, University of Michigan Medical School, Ann Arbor, MI 48109. the effect of ascorbic acid deficiency on the FMO is unrelated to the previously established reduction in the cytochrome P-450 electron transport system.

The present study investigated the biochemical mechanism by which ascorbic acid deficiency causes the reduction in the flavin-containing monooxygenase. Several important properties of FMO isolated from ascorbic-acid-deficient guinea pigs compared to ascorbic-acid-supplemented animals are described in this study. These properties include differences in purification characteristics, effects on the enzyme-cofactor (FAD) relationship, and kinetic properties of the FMO.

\section{MATERIALS AND METHODS}

Materials. Sodium ascorbate, $\mathrm{NADP}^{+}$, NADPH, Triton X-100, DEAE-cellulose, and blue-2-agarose type $3000-\mathrm{CL}$ were purchased from the Sigma Chemical Co. (St. Louis, MO). Dimethylaniline was purchased from the Fisher Scientific Co. (Fair Lawn, NJ). Thiobenzamide and $n$-octylamine were purchased from the Aldrich Chemical Co. (Milwaukee, WI) p-Nitroanisole, $N, N, N^{\prime}, N^{\prime}$-tetramethylethylenediamine and $p$-nitrophenol were purchased from Eastman Kodak (Rochester, NY). Acrylamide and $N, N^{\prime}$-methylene bisacrylamide were purchased from International Biotechnologies, Inc. (New Haven, CT). 2',5'-ADP Sepharose was purchased from P-L Biochemicals (Milwaukee, WI). Sodium dodecyl sulfate was purchased from BDH Chemicals Ltd. (Poole, England). Ascorbic-acid-deficient diet (guinea pig pelleted) was obtained from Nutritional Biochemicals (Cleveland, $\mathrm{OH}$ ). Male Hartley guinea 
pigs were purchased from the Michigan Department of Public Health (Lansing, MI). All chemicals used were of reagent grade or better.

Guinea pigs. Guinea pigs were pair-fed, and the microsomal pellet was prepared as previously described [13].

Purification of flavin-containing monooxygenase. The FMO was purified by the modification of previously established procedures $[8,15]$. The microsomal pellet was adjusted to $15-20 \mathrm{mg}$ protein $/ \mathrm{ml}$ with $10 \mathrm{mM}$ potassium phosphate, $\mathrm{pH} 7.8,1 \mathrm{mM}$ EDTA, 20\% glycerol (buffer A). Solubilization of the FMO was achieved by the addition of an equal volume of buffer A containing 1\% Triton X-100. After stirring for $25 \mathrm{~min}$ at $4^{\circ}$, the mixture was centrifuged for $1.5 \mathrm{hr}$ at $100,000 \mathrm{~g}$ to ensure solubilization. Approximately $9 \mathrm{ml}$ of solubilized microsomes $(8 \mathrm{mg} / \mathrm{ml})$ was applied directly to a column of DEAE-cellulose $(0.9 \mathrm{~cm} \times 19 \mathrm{~cm})$. The FMO was eluted with the equilibration buffer B (buffer A containing $0.2 \%$ Triton $\mathrm{X}-100$ ). The FMO was not retained on this column. The eluate containing FMO enzyme was loaded onto a column of blue 2-agarose type $3000-\mathrm{CL}(0.9 \mathrm{~cm} \times 14 \mathrm{~cm})$ which was pre-equilibrated with buffer B (buffer A containing $0.2 \%$ Triton). Approximately $9 \mathrm{ml}$ of DEAE-purified FMO $(2.5 \mathrm{mg} / \mathrm{ml})$ was applied to the blue agarose column which had a flow rate of $6 \mathrm{ml} / \mathrm{hr}$. The column was washed with 10 column volumes of buffer $B$, and FMO activity was eluted with a linear gradient ( 20 column volumes) of $0-1 \mathrm{M} \mathrm{KCl}$ in buffer $\mathrm{B}$. Fractions containing FMO activity were pooled and dialyzed against buffer $B$. The dialyzed pooled fraction $(14 \mathrm{ml})$ was applied to a column of $2^{\prime}, 5^{\prime}$-ADP Sepharose $(0.5 \mathrm{~cm} \times 8 \mathrm{~cm})$ which was pre-equilibrated with buffer $C$ (buffer A containing $0.5 \%$ Triton X-100). The column had a flow rate of $6 \mathrm{ml} /$ hr. The column was washed with 10 column volumes of $5 \mathrm{mM}$ 2'-AMP in buffer C, and FMO activity was eluted with $0.1 \mathrm{mM}$ NADPH in buffer $C$ ( 10 column volumes). The flavin-containing monooxygenase was purified 50-fold. The FMO was dialyzed against buffer $A$ and concentrated prior to SDS-PAGE. Since the ascorbic-acid-deficient guinea pig FMO was highly labile following the $2^{\prime}, 5^{\prime}$-ADP Sepharose column chromatography, all kinetic experiments were conducted with FMO eluted from the blue agarose column.

Assay of flavin-containing monooxygenase. The metabolism of dimethylaniline can be measured by following the oxidation of NADPH at $340 \mathrm{~nm}$ [16]. The rate of NADPH disappearance was determined using an Aminco DW-2 UV/vis spectrophotometer in the split-beam mode at $340 \mathrm{~nm}$. The standard assay mixture contained $25 \mathrm{mM}$ sodium phosphate, $100 \mathrm{mM}$ glycine, $\mathrm{pH} 8.4,0.4 \mathrm{mM}$ EDTA, $0.08 \%$ Triton, $3 \mathrm{mM}$ octylamine, $0.125 \mathrm{mM}$ NADPH, and an appropriate amount of enzyme in both the control and experimental cuvettes. Dimethylaniline $(2 \mathrm{mM})$ was added to the experimental cuvette only. FADactivated activity was determined by the addition of $0.05 \mathrm{mM}$ FAD to the incubation media. NADPH and enzyme were included in both the experimental and control cuvettes to account for the substrateindependent NADPH disappearance. In general, the non-dimethylaniline NADPH oxidation was at the most $25 \%$ of the FMO enzyme reaction. The reaction was carried out at $37^{\circ}$ and initiated by the addition of dimethylaniline. Since FAD in the presence of dimethylaniline and the absence of FMO results in the oxidation of NADPH, this non-enzymatic oxidation of NADPH was subtracted from the overall rate observed in the presence of enzyme. The reaction was linear and proportional to enzyme concentration. The reaction rates were determined using a molar absorptivity of $6220 \mathrm{M}^{-1} \mathrm{~cm}^{-1}$ for NADPH. The FAD-activated and non-FAD-activated activity measured by NADPH disappearance was equivalent to the rate of appearance of oxidized product, dimethylaniline $N$-oxide. Dimethylaniline $N$-oxide product was determined by the method of Ziegler and Pettit [17] as modified previously [13].

Thiobenzamide S-oxide. Thiobenzamide $S$-oxide product was determined by the method of Cashman and Hanzlik [18] as modified [13].

p-Nitroanisole O-demethylation. $p$-Nitroanisole Odemethylation was determined by the modified method of Zannoni $[13,19]$.

Protein determination. Protein was determined by the method of Lowry et al. [20], with bovine serum albumin as the standard. Protein samples were dialyzed to remove the Triton X-100 when necessary.

Sodium dodecyl sulfate gel electrophoresis. Polyacrylamide slab gel electrophoresis in the presence of sodium dodecyl sulfate (SDS) was performed using a discontinuous buffer system described by Laemmli [21]. Protein samples $(0.02 \mathrm{ml}$ containing 0.05 to $0.3 \mathrm{mg} / \mathrm{ml}$ ) that had been treated previously with $1 \%$ SDS and $1 \%$ mercaptoethanol at $100^{\circ}$ for 2 min were applied to a $7.5 \%$ acrylamide gel and subjected to electrophoresis in a vertical slab electrophoresis assembly (Hoefer Scientific Instruments). Electrophoresis was carried out at $25 \mathrm{~mA} / \mathrm{gel}$ during separation. The gels were stained in Coomassie blue in $\mathrm{H}_{2} \mathrm{O}$-2-propanol-acetic acid $(65: 25: 10)$ for at least $3 \mathrm{hr}$ and destained at room temperature in the same solvent until the background was cleared. The standard proteins used as molecular weight markers were: phosphorylase B, 92,500; bovine serum albumin, 66,200; ovalbumin, 45,000; carbonic anhydrase, 31,000 ; and soybean trypsin inhibitor, 21,500.

\section{RESULTS}

The flavin-containing monooxygenase was partially purified from ascorbic-acid-supplemented and -deficient guinea pig livers by DEAE-cellulose and blue-2-agarose $3000-\mathrm{CL}$ chromatography. The ascorbic-acid-supplemented guinea pig FMO eluted from the blue agarose column in two regions: an FAD-activated region at $0.36 \mathrm{M} \mathrm{KCl}$ (region $\mathrm{A}$ ) and a non-FAD-activated region at $0.51 \mathrm{M} \mathrm{KCl}$ (region B) (Fig. 1). Region A enzyme required the addition of exogenous FAD for optimal activity. However, FMO activity could be detected in the A region without the addition of exogenous FAD. This enzyme activity may have been derived from the $B$ region. The addition of exogenous FAD to region $B$ had no effect. Since this region had high activity already, this is not surprising. The ascorbic-aciddeficient guinea pig FMO eluted from the blue agarose column in two distinct fractions (Fig. 2). There 


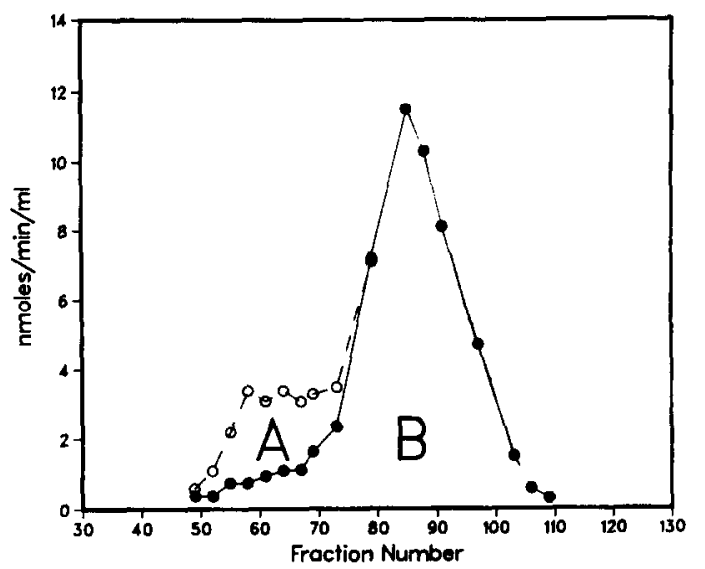

Fig. 1. Elution profile of ascorbic-acid-supplemented guinea pig hepatic flavin-containing monooxygenase by blue-2-agarose 3000-CL column chromatography. FMO was purified from solubilized microsomes as described in Materials and Methods. FMO activity was eluted with a 0 $1 \mathrm{M} \mathrm{KCl}$ gradient and monitored by NADPH oxidation as described in Materials and Methods. The non-FADactivated fraction was determined without the addition of exogenous FAD. Region A: fractions $46-70$; region B: fractions 75-110. Key: (O) FAD-activated fraction; and (O) non-FAD-activated fraction.

was no detectable activity in the $\mathrm{A}$ region without the addition of exogenous FAD. This is in contrast to the equivalent fraction obtained from the ascorbicacid-supplementcd preparation (Fig. 1). Furthermore, there was a marked reduction in the non-

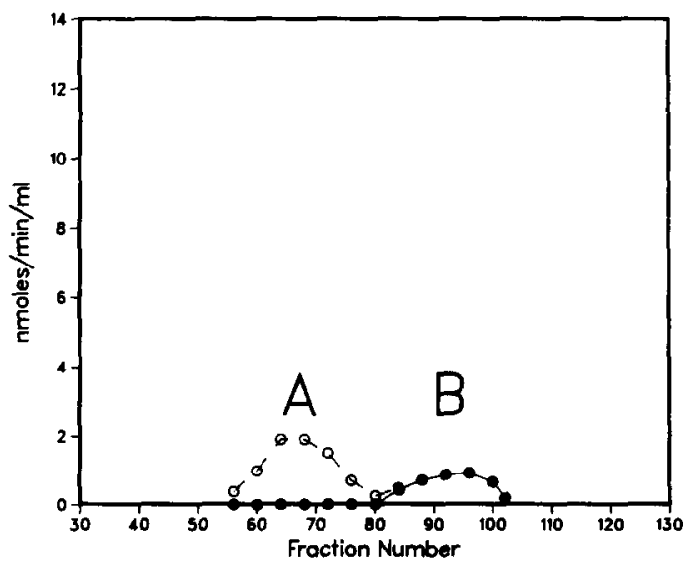

Fig. 2. Elution profile of ascorbic-acid-deficient guinea pig hepatic flavin-containing monooxygenase by blue-2agarose $3000-\mathrm{CL}$ column chromatography. FMO was purified from solubilized microsomes as described in Materials and Methods. Flavin-containing monooxygenase activity was eluted with a $0-1 \mathrm{M} \mathrm{KCl}$ gradient and monitored by NADPH oxidation as described in Materials and Methods. The non-FAD-activated fraction was determined without the addition of exogenous FAD. The FMO activity was non-detectable without the addition of exogenous FAD in fractions 55-80. The limit of detection of the assay was $0.47 \mathrm{nmol} \cdot \mathrm{min}^{-1} \cdot \mathrm{ml}^{-1}$. Region A: fractions $55-80$; region B: fractions 80-105. Key: (O) FAD-activated fraction; and (O) non-FAD-activated fraction.
FAD-activated FMO activity (region B) with enzyme purified from ascorbic-acid-deficient animals compared to ascorbic-acid-supplemented ones (Figs. 1 and 2).

Table 1 summarizes the purification and recovery of FMO isolated from ascorbic-acid-deficient and -supplemented guinea pig hepatic microsomal preparations. In the original microsomal preparation, there was a 4-fold reduction in the ascorbic-aciddeficient guinea pig microsomal FMO specific activity compared to the ascorbic-acid-supplemented guinea pigs $\left(11.7 \mathrm{nmol} \cdot \mathrm{min}^{-1} \cdot \mathrm{mg}^{-1}\right.$ vs 2.8$)$. The quantitative reduction in FMO activity with ascorbic acid deficiency was maintained during purification $\left(86.7 \mathrm{nmol} \cdot \mathrm{min}^{-1} \cdot \mathrm{mg}^{-1}\right.$ vs 17$)$. Recovery of ascorbicacid-supplemented guinea pig FMO from the blue agarose column was $35 \%$ of the initial microsomal activity. Only $5 \%$ of the total microsomal activity was FAD-activated enzyme (Table 1). In contrast, $22 \%$ of the microsomal ascorbic-acid-deficient FMO was recovered from the blue agarose column and $15 \%$ of this activity was FAD-activated activity, 3fold more than was found with the ascorbic-acidsupplemented guinea pig FMO. In spite of this substantial FAD activation on ascorbic-acid-deficient enzyme, the total quantity of recoverable enzyme did not approach enzyme prepared from ascorbic-acid-supplemented animals $(45 \mathrm{nmol} / \mathrm{min}$ vs 274).

Ascorbic-acid-supplemented and -deficient guinea pig liver FMO which eluted from the blue agarose column in the B region was further purified by a $2^{\prime}, 5^{\prime}$-ADP Sepharose column and subjected to SDSPAGE (Fig. 3). Previous studies have indicated that hog liver FMO has a molecular weight of 56,000 when subjected to SDS-PAGE [22]. The ascorbicacid-deficient guinea pig FMO exhibited a distinct decrease in protein banding in the 56,000 dalton region compared to the ascorbic-acid-supplemented enzyme. Furthermore, this quantitative decrease was also observed when FMO partially purified by DEAE-cellulose and blue-2-agarose $3000-C L$ was subjected to SDS-PAGE.

In addition to the $\mathrm{N}$-oxidation of dimethylaniline, the metabolism of thiobenzamide, a sulfur FMO substrate, was also activated by FAD in the presence of FAD-activated enzyme. Also, the activation by FAD appeared to be specific for FAD in that the addition of ascorbic acid $(0.025$ to $1.0 \mathrm{mM})$ did not have an effect on the enzyme. There was no significant difference in the apparent affinity constants $\left(K_{m}\right)$ of the FAD-activated and non-FAD-activated FMO from both ascorbic-acid-supplemented and -deficient guinea pig for dimethylaniline and NADPH (Table 2). The $K_{m}$ of dimethylaniline was in the order of $3 \times 10^{-4} \mathrm{M}$ for all four enzyme fractions. In addition, the $V_{\max }$ for dimethylaniline with FAD-activated FMO from both the ascorbic-acidsupplemented and -deficient animals was $1.0 \mathrm{nmol} /$ min and with non-FAD-activated enzyme was 3.7 for the ascorbic-acid-supplemented animals compared to 1.3 for the ascorbic-acid-deficient animals. The $K_{m}$ of NADPH for the FAD-activated FMO was $2.0 \times 10^{-5} \mathrm{M}$ and $5.0 \times 10^{-5} \mathrm{M}$ for the non-FADactivated FMO prepared from ascorbic-acid-supplemented guinea pigs. Similarly, the $K_{m}$ of NADPH 
Table 1. Purification of flavin-containing monooxygenase with DEAE-cellulose and blue agarose column chromatography

\begin{tabular}{|c|c|c|c|c|c|}
\hline Fraction & $\begin{array}{l}\text { Volume } \\
\text { (ml) }\end{array}$ & $\begin{array}{c}\text { Protein } \\
(\mathrm{mg} / \mathrm{ml})\end{array}$ & $\begin{array}{l}\text { Specific activity } \\
(\mathrm{nmol} / \mathrm{min} / \mathrm{mg})\end{array}$ & $\begin{array}{c}\text { Total activity } \\
\text { (nmol/min) }\end{array}$ & $\begin{array}{c}\text { Recovery } \\
(\%)\end{array}$ \\
\hline \multicolumn{6}{|l|}{ Ascorbic acid supplemented } \\
\hline $100,000 \mathrm{~g}$ microsome & 4.5 & 15.20 & 11.7 & 790 & 100 \\
\hline $\begin{array}{l}\text { Blue agarose } \\
\text { (FAD-activated plus non-FAD-activated) }\end{array}$ & 40.0 & 0.08 & 86.7 & 274 & 35 \\
\hline FAD-activated & 15.0 & 0.07 & 39.2 & 40 & 5 \\
\hline Non-FAD-activated & 25.0 & 0.09 & 110.0 & 234 & 30 \\
\hline \multicolumn{6}{|l|}{ Ascorbic acid deficient } \\
\hline $100,000 \mathrm{~g}$ microsome & 4.2 & 18.00 & 2.8 & 208 & 100 \\
\hline $\begin{array}{l}\text { Blue agarose } \\
\text { (FAD-activated plus non-FAD-activated) }\end{array}$ & 40.0 & 0.07 & 17.0 & 45 & 22 \\
\hline FAD-activated & 20.0 & 0.05 & 28.3 & 30 & 15 \\
\hline Non-FAD-activated & 20.0 & 0.08 & 9.4 & 15 & 7 \\
\hline
\end{tabular}

Flavin-containing monooxygenase activity was monitored by NADPH oxidation as described in Materials and Methods. The average hepatic level of ascorbic acid in supplemented animals was $29 \pm 13 \mathrm{mg} / 100 \mathrm{~g}$ wet liver weight and $1.8 \pm 1.3 \mathrm{mg}$ in deficient animals.

for the FAD-activated FMO was $2.8 \times 10^{-5} \mathrm{M}$ and $7.3 \times 10^{-5} \mathrm{M}$ for the non-FAD-activated FMO prepared from ascorbic-acid-deficient guinea pigs. The $K_{m}$ for FAD with purified enzyme preparations

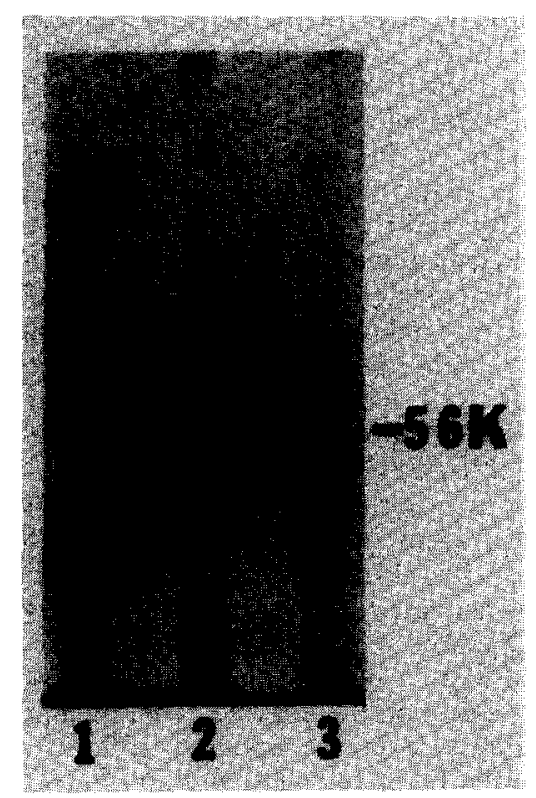

Fig. 3. SDS electrophoresis of partially purified hepatic FMO prepared from ascorbic-acid-supplemented and -deficient guinea pigs. Electrophoresis was performed in $7.5 \%$ polyacrylamide gel as described in Materials and Methods. The direction of migration was from top to bottom. Protein was loaded as follows: lane 1, standards, $6 \mu \mathrm{g}$; lane 2, ascorbic-acid-supplemented guinea pig purified (50-fold) FMO, $2.5 \mu \mathrm{g}$; lane 3, ascorbic-acid-deficient guinea pig purified (50-fold) FMO, $2.5 \mu \mathrm{g}$. The average hepatic level of ascorbic acid in supplemented animals was $29 \pm 13 \mathrm{mg} / 100 \mathrm{~g}$ wet liver weight and $1.8 \pm 1.3 \mathrm{mg}$ in the deficient animals. The protein standards were: phosphorylase $B, 92,500$; bovine serum albumin, 66,200 ; ovalbumin, 45,000; carbonic anhydrase, 31,000; and soybean trypsin inhibitor, 21,500 . from ascorbic-acid-deficient guinea pigs and from ascorbic-acid-supplemented animals was in the order of $6 \times 10^{-7} \mathrm{M}$.

The non-FAD-activated enzyme was found to demonstrate a time-dependent nonlinearity (Fig. 4). Ascorbic-acid-deficient guinea pig FMO had an initial reaction rate which was linear for approximately $100 \mathrm{sec}$ in the presence of $2 \mathrm{mM}$ dimethylaniline, the usual substrate concentration. By $400 \mathrm{sec}$ only $10 \%$ of this initial rate was maintained. In contrast, the non-FAD-activated FMO from ascorbic-acid-supplemented guinea pigs still had $60 \%$ of its initial rate after $400 \mathrm{sec}$. The inhibition of metabolism was found to be dependent on the concentration of dimethylaniline (Table 3). As the concentration of dimethylaniline was reduced from 2 to $0.08 \mathrm{mM}$, the degree of inhibition was reduced from 90 to $50 \%$ for the ascorbic-acid-deficient guinea pig FMO and from 40 to $10 \%$ for the ascorbic-acidsupplemented guinea pig FMO. The nonlinearity could not be prevented by EDTA, $0.4 \mathrm{mM}$; benzoate, $50 \mathrm{mM}, 12.5 \mathrm{mM}$; dimethyl sulfoxide, $50 \mathrm{mM}$; ascorbate, $1 \mathrm{mM}, 0.2 \mathrm{mM}$; or catalase. $0.4 \mu \mathrm{g} / 14 \mu \mathrm{g}$ enzyme protein. In addition to the enhanced sensitivity to time-dependent nonlinearity with purified enzyme from ascorbic-acid-deficient guinea pigs, the enzyme was also very labile upon freezing. Purified enzyme prepared from ascorbic-acid-supplemented guinea pigs was stable for 4 weeks at $-20 \%$, whereas the activity of the enzyme prepared from ascorbicacid-deficient animals was non-detectable.

\section{DISCUSSION}

Our previous study demonstrated an in vivo requirement for ascorbic acid to maintain the FMO [13]. The present study deals with the biochemical basis for the participation of ascorbic acid with the FMO. Evidence is presented which indicates that qualitative and quantitative differences occur between FMO isolated from ascorbic-acid-deficient and -supplemented guinea pig livers.

The reduction in hepatic FMO activity with ascor- 
Table 2. Apparent affinity constants for flavin-containing monooxygenase

\begin{tabular}{lccc}
\hline Fraction & & \multicolumn{3}{c}{$K_{m}(\mathrm{M})$} & \\
\cline { 2 - 4 } & Dimethylaniline & NADPH & FAD \\
\hline Ascorbic acid supplemented & & & \\
FAD-activated fraction & $2.1 \times 10^{-4}$ & $2.0 \times 10^{-5}$ & $5.0 \times 10^{-7}$ \\
Non-FAD-activated fraction & $3.2 \times 10^{-4}$ & $5.0 \times 10^{-5}$ & \\
Ascorbic acid deficient & $3.4 \times 10^{-4}$ & $2.8 \times 10^{-5}$ & $6.7 \times 10^{-7}$ \\
$\quad$ FAD-activated fraction & $3.3 \times 10^{-4}$ & $7.3 \times 10^{-5}$ & \\
Non-FAD-activated fraction & & & \\
\hline
\end{tabular}

Partially purified flavin-containing monooxygenase activity was monitored by NADPH oxidation as described in Materials and Methods. Kinetic data were obtained by measuring FMO activity using at least five different concentrations of dimethylaniline, NADPH, or FAD from 0.2 to 5 times the $K_{m}$ value. The non-FAD-activated fraction was determined without the addition of exogenous FAD, and exogenous FAD had no effect on the activity determined in this fraction. Each value represents the mean of at least two experiments.

bic acid deficiency could result from a qualitative alteration in the enzyme which impedes the oxidation mechanism by which substrates are metabolized. Ascorbic acid deficiency could be disrupting this process by altering the binding of NADPH, oxygen, FAD or, for that matter, the xenobiotic itself. Another possibility is that ascorbic acid deficiency causes an alteration in the active enzyme complex which interferes with the electron flow through the transport cycle. In view of the fact that there is no alteration in the affinity $\left(K_{m}\right)$ for dimethylaniline or NADPH with purified ascorbic-acid-deficient guinea pig FMO, it is most likely that ascorbic acid defi-

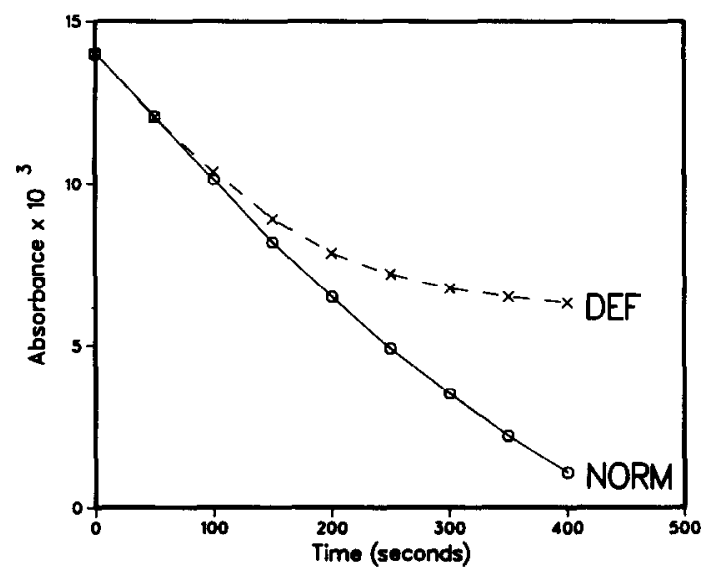

Fig. 4. Time-dependent nonlinearity of non-FAD-activated FMO activity with $2 \mathrm{mM}$ dimethylaniline. FMO activity was monitored by following the rate of NADPH oxidation at $340 \mathrm{~nm}$ as described in Materials and Methods. The initial rate of metabolism was adjusted to be the same for the ascorbic acid supplemented and deficient guinea pigs by varying the amount of enzyme in the incubation media. The same degree of time-dependent nonlinearity was observed when the incubation media contained the same protein concentration and the same concentration of Triton $\mathrm{X}-100$ for both the ascorbic-acid-supplemented and -deficient guinea pigs. Key: (O) ascorbic-acidsupplemented guinea pig FMO; and $(x)$ ascorbic-aciddeficient guinea pig FMO. ciency is not causing a reduction in FMO activity by altering the affinity for substrate of NADPH.

FAD-activated FMO was recovered from both the ascorbic-acid-supplemented and -deficient guinea pigs. This enzyme may represent a form of FMO which binds FAD with a lower affinity. Since the FAD-activated FMO from both the ascorbic-acidsupplemented and -deficient guinea pigs had an FAD affinity $\left(K_{m}\right)$ in the order of $6 \times 10^{-7} \mathrm{M}$, this hypothesis cannot be confirmed at this time. Purified ascorbic-acid-deficient guinea pig FMO is more dependent than the ascorbic-acid-supplemented guinea pig on the addition of exogenous FAD for optimal activity. Three-fold more of the ascorbic-

Table 3. Inhibition of flavin-containing monooxygenase by dimethylaniline

\begin{tabular}{ccc}
\hline $\begin{array}{c}\text { Dimethylaniline } \\
(\mathrm{mM})\end{array}$ & \multicolumn{2}{c}{ Metabolism rate after $400 \mathrm{sec}$} \\
\cline { 2 - 3 } & $\begin{array}{c}\text { Initial rate of metabolism } \\
\text { Ascorbic acid } \\
\end{array}$ & $\begin{array}{c}\text { Ascorbic acid } \\
\text { deficient }\end{array}$ \\
\hline 2.00 & 0.6 & 0.1 \\
0.80 & 0.6 & 0.1 \\
0.40 & 0.6 & 0.4 \\
0.24 & 0.6 & 0.4 \\
0.12 & 0.7 & 0.5 \\
0.08 & 0.9 & 0.5 \\
\hline
\end{tabular}

Non-FAD-activated flavin-containing monooxygenase activity was monitored by NADPH oxidation as described in Materials and Methods. The concentration of dimethylaniline used in each assay is indicated in the table. The initial rate of metabolism was adjusted to be the same for the ascorbic-acid-supplemented and -deficient guinea pigs by varying the amount of enzyme in the incubation media. The same degree of time-dependent nonlinearity was observed when the incubation media contained the same protein concentration and the same concentration of Triton $\mathrm{X}-100$ for both the ascorbic-acid-supplemented and -deficient guinea pigs. Each value represents the mean of two experiments. 
acid-deficient guinea pig FMO, recovered from the blue agarose column, required exogenous FAD than the ascorbic-acid-supplemented enzyme. Ascorbic acid deficiency may be causing an enhancement in the FAD dependency by either altering the association between the apoenzyme and FAD or modifying the enzyme in such a manner that the flow of electrons necessary for substrate oxidation is impeded. Since there was no difference in the affinity $K_{m}$ for FAD with FAD-activated ascorbic-acid-deficient guinea pig FMO compared to FAD-activated ascorbic-acid-supplemented animals, ascorbate deficiency does not appear to alter the binding of FAD to the apoenzyme.

In keeping with this, the possibility that ascorbic acid may have a role in the transfer of electrons is suggested by the electron donating capacity of this vitamin [23]. However, the addition of ascorbic acid to the incubation media of FAD-activated FMO did not result in an activation of the enzyme. One cannot discount the possibility, though, that upon purification the sterochemical relationship between vitamin, cofactor and apoenzyme may be such that the vitamin is incapable of operating effectively under these in vitro conditions.

Ascorbic acid deficiency could also be indirectly affecting the flow of electrons. The addition of exogenous FAD to the microsomal preparation had no effect on the activity of the FMO. Therefore, the microsomal milieu appears to prevent the alteration of the enzyme from occurring, but once the enzyme is solubilized it is sensitive to this FAD dependency. The potential importance of the microsomal environment to electron transfer has been demonstrated by the cytochrome P-450 electron transport system which is dependent on the presence of phosphatidylcholine for electron transfer [24]. In addition, it has been suggested that the active FMO complex exists as aggregates of several monomeric units and that the active enzyme is an octamer which is in equilibrium with tetrameric forms [22]. Therefore, possibly in ascorbic acid deficiency the membrane environment is altered in such a manner that the aggregation of the enzyme needed for product formation is inhibited. The addition of exogenous FAD could enable the enzyme to overcome this uncoupling of the oxidative mechanism.

The enhanced sensitivity of purified ascorbic aciddeficient guinea pig FMO to time-dependent nonlinearity supports the theory that ascorbic acid deficiency results in an impairment of the oxidative mechanism. The nonlinearity was found to follow an initial lag period and was dependent on the substrate concentration. The degree of nonlinearity decreased as the concentration of substrate was decreased below the $K_{m}$. These two facts suggest that the nonlinearity may be related to either a product formed or the turnover of the enzyme. The time-dependent nonlinearity does not appear to be related to the formation of a secondary reactive oxygen product, since the nonlinearity could not be prevented by ascorbic acid, EDTA, benzoate, dimethyl sulfoxide or catalase. The second possibility, that the timedependent nonlinearity is related to the enzyme turnover, supports the theory that ascorbic-acid-deficient guinea pig FMO may be altered in such a manner that the process of electron transfer is vulnerable. Although the enzyme is initially able to oxidize the substrate, the stress of electron transfer may result in a progressive decay of this process. Additional evidence for the instability of the active complex of the ascorbic-acid-deficient guinea pig FMO is the high lability that occurs upon freezing purified ascorbic-acid-deficient guinea pig FMO as compared to ascorbic-acid-supplemented fractions.

The results of this study also suggest the possibility that ascorbic acid deficiency results in a quantitative reduction in the FMO. In the original microsomal preparation, there was a 4-fold reduction in the specific activity of the ascorbic-acid-deficient guinea pig microsomal FMO compared to the ascorbic-acidsupplemented animals. Following purification, even with FAD activation, this reduction in activity was maintained. The decrease in FMO specific activity could be related to either the presence of inactive enzyme or a quantitative alteration in the ascorbicacid-deficient enzyme. A quantitative reduction in ascorbic-acid-deficient guinea pig FMO is indicated by a consistent decrease in protein staining intensity at the 56,000 molecular weight band with both partially purified and purified enzyme compared to ascorbic-acid-supplemented FMO. Although the decrease observed in the relative staining intensity may reflect changes in the quantity of FMO, immunoelectrophorectic techniques would be helpful to substantiate and confirm a quantitative decrease of the FMO under ascorbic acid deficiency.

\section{REFERENCES}

1. D. M. Ziegler, in Enzymatic Basis of Detoxification (Ed. W. B. Jakoby), Vol. 1, p. 201. Academic Press, New York (1980).

2. R. A. Prough, P. C. Freeman and R. N. Hines, J. biol. Chem. 256, 4178 (1981).

3. L. L. Poulsen, Rev, Biochem. Toxic. 3, 33 (1981),

4. N. P. Hajjar and E. Hodgson, Science 209, 1134 (1980).

5. R. A. Prough, Archs Biochem. Biophys. 158, 442 (1973).

6. E. Chiele and G. Malvaldi, Toxicology 31, 41 (1984).

7. T. Kimura, M. Kodama and C. Nagata, Biochem. biophys. Res. Commun. 110, 640 (1983).

8. P. J. Sabourin and E. Hodgson, Chem. Biol. Interact. 51, 125 (1984).

9. D. E. Williams, S. E. Hale, A. S. Muerhoff and B. S. S. Masters, Molec. Pharmac. 28, 381 (1985).

10. T. R. Devereux and J. R. Fouts, Drug Metab. Dispos. 3, 254 (1975).

11. M. W. Duffel, J. M. Graham and D. M. Ziegler, Molec. Pharmac. 19, 134 (1981).

12. A. Dixit and T. E. Roche, Archs Biochem. Biophys. 233, 50 (1984).

13. J. I. Brodfuehrer and V. G. Zannoni, Biochem. Pharmac. 35, 637 (1986).

14. V. G. Zannoni and M. M. Lynch, Drug Metab. Rev. 2, 57 (1973).

15. D. M. Ziegler and L. L. Poulsen, in Methods of Enzymology (Eds. S. Fleischer and L. Packer), Vol. 52, Part C, p. 142. Academic Press, New York (1978).

16. R. E. Tynes and E. Hodgson, Archs Biochem. Biophys. 240, 77 (1985).

17. D. M. Ziegler and F. H. Pettit, Biochem. biophys. Res. Commun. 15, 188 (1964).

18. J. R. Cashman and R. P. Hanzlik, Biochem. biophys. Res. Commun. 98, 147 (1981).

19. V. G. Zannoni, Fundamentals of Drug Metabolism and 
Drug Disposition (Eds. B. N. La Du, H. G. Mandel and E. L. Way), p. 556. Williams \& Wilkins, Baltimore (1971).

20. O. H. Lowry, N. J. Rosebrough, A. L. Farr and R. J. Randall, J. biol. Chem. 193, 265 (1951).

21. U. K. Laemmli, Nature, Lond. 227, 680 (1970).
22. L. L. Poulsen and D. M. Ziegler, J. biol. Chem. 254, 6449 (1979).

23. H. Staudinger, K. Krisch and S. Leonhauser, Ann. N.Y. Acad. Sci. 92, 195 (1961).

24. H. W. Strobel, A. Y. Lu, J. Heidema and M. J. Coon, J. biol. Chem. 245, 4851 (1970). 